\title{
Feature analysis of stratospheric wind and temperature fields over the Antigua site by rocket data
}

\author{
Yang Li' ${ }^{1}$, Zheng Sheng ${ }^{1,2^{*}}$, and JinRui Jing ${ }^{1}$ \\ ${ }^{1}$ College of Meteorology and Oceanography, National University of Defense Technology, Nanjing 211100, China; \\ ${ }^{2}$ Collaborative Innovation Center on Forecast and Evaluation of Meteorological Disasters, Nanjing University of Information Science and Technology, Nanjing \\ 211100, China
}

\begin{abstract}
The wind and temperature fields at 20 to $55 \mathrm{~km}$ above the Antigua launch site $\left(17^{\circ} \mathrm{N}, 61^{\circ} \mathrm{W}\right)$ were analyzed by using sounding rocket data published by the research organization on Stratosphere-Troposphere Processes and their Role in Climate (SPARC). The results showed distinct variations in the wind and temperature fields at different heights from the 1960s to the 1990s. The overall zonal wind speed showed a significant increasing trend with the year, and the overall change in meridional wind speed showed a falling trend from 1976 to 1990, whereas the temperature field showed a significant cooling trend from 1964 to 1990. The times the trends mutated varied at different levels. By taking the altitudes at 20,35 , and $50 \mathrm{~km}$ as representatives, we found that the zonal wind speed trend had mutated in 1988, 1986, and 1986, respectively; that the meridional wind speed trend had mutated in 1990, 1986, and 1990, respectively; and that the temperature trend had mutated separately in 1977, 1973, and 1967, respectively. Characteristics of the periodic wind and temperature field variations at different heights were also analyzed, and obvious differences were found in time scale variations across the different layers. The zonal and meridional wind fields were basically characterized as having a significant periodic variation of 5 years across the three layers, and each level was characterized as having a periodic variation of less than 5 years. Temperature field variation at the three levels was basically characterized as occurring in 10-year and 5-year cycles.
\end{abstract}

Keywords: wind field change; temperature change; empirical orthogonal function (EOF); wavelet analysis

Citation: Li, Y., Sheng Z., and Jing, J. R. (2019). Feature analysis of stratospheric wind and temperature fields over the Antigua site by rocket data. Earth Planet. Phys., 3(5), 414-424. http://doi.org/10.26464/epp2019040

\section{Introduction}

Because of constraints imposed by global dynamics, the temperature of the stratosphere increases with altitude (Held and O'Brien, 1992; Zhang $M$ et al., 2015). However, the distribution of the power fields within the stratosphere is unique. The bottom of the stratosphere is usually affected by the westerly zone of the troposphere, and it blows to the west. Moreover, the middle and upper layers have monsoons, with easterly winds prevailing in summer and westerly winds prevailing in winter. Some significant dynamic and thermodynamic phenomena also occur frequently in the stratosphere, such as explosive warming, periodic oscillation, and atmospheric circulation. In addition, the limited means available for direct detection of the wind field and the relatively scarce observation data present challenges to investigating changes in the atmospheric wind field in the stratosphere (Xiao WH et al., 2012). Changes in dynamic fields in the stratosphere directly affect the movements of the tropospheric atmosphere. To understand the formation of and variation in the tropospheric climate and the physical mechanisms of medium- and long-term evolution of the atmospheric circulation, research on the evolution of and vari-

Correspondence to: S. Zheng, 19994035@sina.com

Received 01 APR 2019; Accepted 18 JUN 2019.

Accepted article online 12 JUL 2019.

(C) 2019 by Earth and Planetary Physics. ations in the stratospheric atmospheric circulation and its physical mechanisms has become an important field within atmospheric science and space science (Huang RH et al., 2018).

As early as 1984, Xiao YS (1984) analyzed and discussed the baroclinic instability under different layers of high and low altitudes and wind speed vertical profiles. In addition, Wu YF (1994) made observations on mesoscale wind shear in 1994, and Xu BQ et al. (2014) used the least squares method to analyze and study the wind shear index to gain a deeper understanding of the characteristics and stability of the stratospheric wind shear structure. To study the stratospheric wind field, Xiao WH et al. (2012) calculated the atmospheric wind field by using monthly mean data from the COSMIC (Constellation Observing System for Meteorology, lonosphere, and Climate) occultation observation, such as the pressure intensity, refractive index, height, and temperature. They then compared their results with the wind field results analyzed by the European Centre for Medium-Range Weather Forecasts (ECMWF) to obtain the variation rules of the atmospheric wind field at middle and high latitudes. Liu J et al. (2017) used the NCEP (National Centers for Environmental Prediction) Reanalysis wind field data to show that the wind field environment at the bottom of the stratosphere in the Xinjiang region had obvious seasonal and spatial variation characteristics and that the wind direction and speed in the quasi-zero wind layer had obvious seasonal variation characteristics. Liu MZ et al. (2016) used rocket 
data to study the monthly average wind field and its 2-year, annu$\mathrm{al}$, and half-year variation characteristics at the Kwaj station $\left(8^{\circ} \mathrm{N}\right.$, $167^{\circ} \mathrm{E}$ ) in the United States, and then compared their results with the wind field model. To study the periodic oscillation of the stratosphere, Chen BQ et al. (2018) conducted a study on the temporal and spatial distribution characteristics of the quasi-zero wind layer based on the empirical orthogonal function (EOF) method for the interim day-to-day reanalysis data. The results showed that low-latitude regions were mainly affected by the quasi-biennial oscillation (QBO). Han PC and Jian MQ (2016) used stratospheric sounding data and ECMWF grid data to analyze the tropical stratospheric zonal wind QBO. Their results indicated that the QBO cycle has significant decadal changes. Huang RH et al. (2018) also reviewed and summarized the research progress on stratospheric atmospheric circulation. Their results indicated the importance of research on stratospheric atmospheric dynamics.

To study temperature, Wang LJ et al. (2015) used historical sounding rocket data to investigate the long-term trend of static stability of the middle atmosphere from the equator to the middle latitude of the northern hemisphere from 1962 to 1991. In addition, Chang QH et al. (2006) used one-year Rayleigh lidar data to investigate the characteristics of static stability at altitudes of 30 to 60 $\mathrm{km}$ over Wuhan, China. The results showed that in the upper stratosphere to the middle of the mesosphere $(48-60 \mathrm{~km})$, the atmospheric static stability at all sites presented a long-term trend of significant weakening. The change in stratospheric temperature has been observed and studied abroad. Observational data show that from 1979 to 1994 , the average annual temperature of the stratosphere in the mid-latitude region of the northern hemisphere had obvious changes and that the higher the altitude was, the more the temperature decreased (Ramaswamy et al., 2001). Simulations conducted by Brasseur et al. (1988) and Brühl and Crutzen (1988) showed that the temperature of the stratopause had dropped by up to $16-22 \mathrm{~K}$ at the end of the 21 st century. Santer et al. (1996) used the results of a long-term simulation experiment with an atmospheric general circulation model (GCM) to investigate the pattern of variation in the global temperature structure. Their results showed a strong similarity between the simulation and observation analyses. On this basis, the Brunt-Vaisala frequency was used as a proxy to measure the overall characteristics of the atmosphere, and the response form of the Brunt-Vaisala frequency to global warming was investigated through numerical simulation and observational data analysis (Juckes, 2000; Trenberth and Stepaniak, 2003; Frierson, 2006; Frierson and Davis, 2011). For example, Juckes (2000) investigated the role of heating with convective latent heat in controlling the static stability of the mid-latitude, and then speculated that the warming of the mid-latitude troposphere would be accompanied by the enhancement of atmospheric stability. Gardner et al. (2002) investigated the seasonal variation characteristics of atmospheric stability in the altitude range of 80 to $105 \mathrm{~km}$ by using one-year lidar data. Xu J et al. (2010) used radiosonde data to give the temperature variation trend of the average temperature of the global latitudinal circle from 1979 to 2005 in the lower troposphere to 30 $\mathrm{hPa}$. The results showed a very significant stratospheric cooling trend.

Although temperatures based on sounding rocket data have been well researched, studies are lacking on wind speed, especially comprehensive research on the power field and thermal structure of the stratosphere. In this article, we studied the characteristics of the wind and temperature fields at altitudes of 20 to $55 \mathrm{~km}$ above the Antigua site by using sounding rocket data from the 1960 s to the 1990s, and the dynamic and thermodynamic characteristics were combined to provide a comprehensive analysis.

\section{Materials and Methods}

We utilized data from a total of 1,862 sounding rockets over the Antigua station from 1964 to 1990 to analyze the wind and temperature fields from 20 to $55 \mathrm{~km}$ over the Antigua station (www.sparc-climate.org/). Figure 1 shows the distribution of the monthly sounding numbers for the Antigua site.

In EOF decomposition, also known as principal component analysis, the original variable field is decomposed into a linear combination of orthogonal functions, forming a few typical independ-

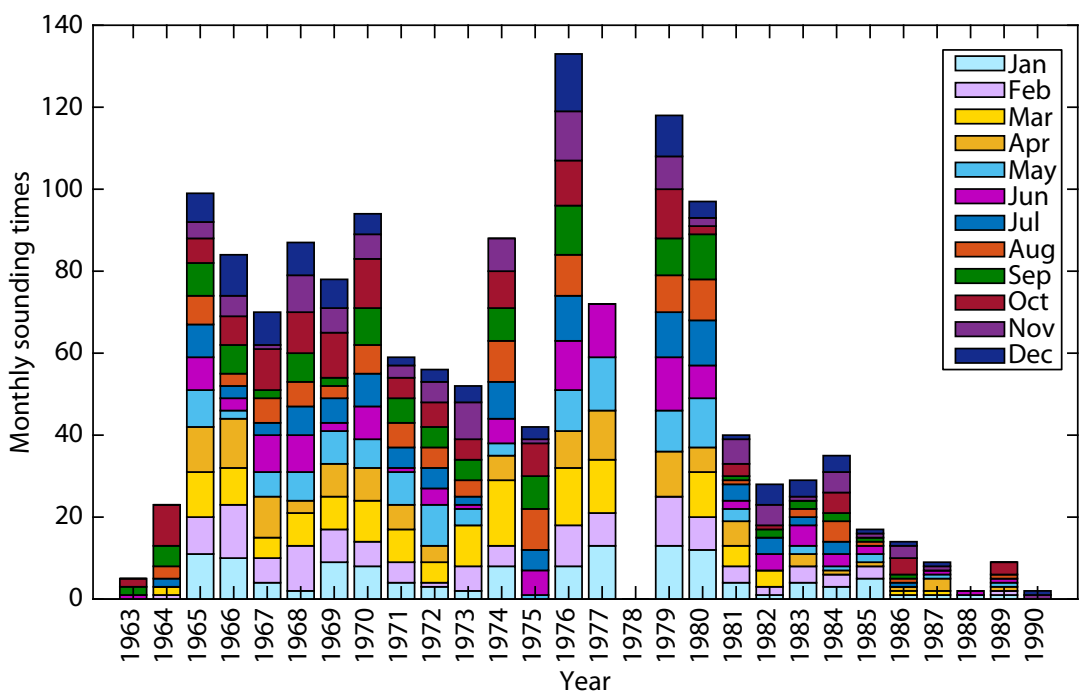

Figure 1. Diagram of the accumulated number of soundings over the Antigua site by month. 
ent modes to replace the original variable field (Wei FY, 1999). In EOF expansion in the climate variable field, the variable field is decomposed into a time function and a space function. The data are processed into the form of departure according to the matrix formula:

$$
\begin{gathered}
C_{m \times m}=\frac{1}{n} \boldsymbol{X} \times \boldsymbol{X}^{\top}, \\
\boldsymbol{C}_{m \times m} \times \boldsymbol{V}=\boldsymbol{V} \times \boldsymbol{\Lambda}, \\
\boldsymbol{T}=\boldsymbol{V}^{\top} \boldsymbol{X}, \\
R_{k}=\frac{\lambda_{k}}{\sum_{i=1}^{m} \lambda_{i}} \times 100 \%, \quad k=1,2, \ldots, j(j<m), \\
e_{j}=\lambda_{j}\left(\frac{2}{n}\right)^{1 / 2}, \quad \lambda_{j}-\lambda_{j+1} \geq e_{j},
\end{gathered}
$$

where $C_{m \times m}$ is the covariance matrix of the anomaly matrix $X ; \Lambda$ and $\boldsymbol{V}$ denote the eigenvalue vector and eigenvector of $\boldsymbol{C}_{m \times m}$, respectively, and $\Lambda$ is the diagonal matrix of the eigenvalue $\lambda=\left(\lambda_{1}, \lambda_{2}\right.$, $\left.\ldots, \lambda_{m}\right) ; T$ is the time coefficient matrix; and $R_{k}$ is the variance contribution. Equation (5) carries out the significance test by calculating the error range of the eigenvalue. If $\lambda_{j}-\lambda_{j+1} \geq e_{j}$ is satisfied, the significance test is passed.

The Mann-Kendall test is then used to test for and analyze the abrupt changes in the wind field and temperature field with time (Wei FY, 1999). For time series $x$ with $n$ sample sizes, an order sequence was constructed:

$$
s_{K}=\sum_{i=1}^{k} r_{i}, \quad r_{i}=\left\{\begin{array}{cc}
1 & x_{i}>x_{j} \\
0 & \text { else }
\end{array} j=1,2, \cdots, i\right.
$$

where order column $s_{K}$ is the cumulative count of the number of values at moment $i$ greater than that of $j$. Under the assumption of random independence of the time series, the statistics are defined as follows:

$$
U F_{k}=\frac{s_{k}-E\left(s_{k}\right)}{\sqrt{\operatorname{Var}\left(s_{k}\right)}}, k=1,2, \cdots, n,
$$

where $U F_{1}=0$ and $E\left(s_{k}\right)$ and $\operatorname{Var}\left(s_{k}\right)$ are the mean and variance of $s_{k}$. When $x_{1}, x_{2}, \ldots, x_{n}$ are independent of each other and have the same continuous distribution, they can be calculated by the following equation:

$$
E\left(s_{k}\right)=\frac{n(n+1)}{4}, \operatorname{Var}\left(s_{k}\right)=\frac{n(n-1)(2 n+5)}{72},
$$

where $U F_{i}$ is a standard normal distribution, which is a statistical sequence calculated on the order of time series $x$. Given the significance level $(a)$, the normal distribution table is checked. If $\left|U F_{i}\right|>$ $U_{a}$, it indicates an obvious trend change in the sequence. The process is then repeated in reverse order of time series $x$, while making $U B_{k}=-U F_{k}$, where $k=(n, n-1, \ldots, 1)$, and $U B_{1}=0$.

Finally, a wavelet analysis is taken to find the time scale change in the wind field and temperature field. The basic idea of a wavelet analysis is to express or approximate a certain signal or function with a cluster of wavelet function systems. The wavelet function is oscillatory, that is, the wavelet function $\psi(t)$ satisfies

$$
\int_{-\infty}^{+\infty} \psi(t)=0, \quad \psi(t) \in L^{2}(R)
$$

where $\psi(t)$ can form a cluster function system by scaling and shift- ing on the time axis (Wei FY, 1999):

$$
\psi_{a, b}(t)=|a|^{-1 / 2} \psi\left(\frac{t-b}{a}\right), \quad a, b \in R, a \neq 0,
$$

where $\psi_{a, b}(t)$ is a subwavelet, $a$ is a scale factor reflecting the period length of the wavelet, and $b$ is a translation factor reflecting the translation in time. The wavelet transform coefficient $W_{f}(a, b)$ can then be obtained from the subwavelet:

$$
W_{f}(a, b)=|a|^{-1 / 2} \int_{R} f(t) \bar{\psi}\left(\frac{t-b}{a}\right) \mathrm{d} t
$$

where $f(t)$ is a signal or square-integrable function, $a$ is the expansion scale, $b$ is the translation parameter, and $\bar{\psi}\left(\frac{t-b}{a}\right)$ is the complex conjugate function of $\psi\left(\frac{t-b}{a}\right)$. In practical application, wavelet coefficients are mainly used to analyze the time-frequency variation characteristics of the time series.

\section{Analysis of Characteristics of the Wind and}

\section{Temperature Fields over the Antigua Station}

The results of the EOF analysis show that the variance contributions of the first three modes of the zonal wind field over the Antigua station are $82.6 \%, 7.8 \%$, and $6.1 \%$, respectively, whereas for the meridional wind field, they are $46.9 \%, 22.8 \%$, and $15.1 \%$, respectively, and for the temperature field, they are $79.1 \%, 5.9 \%$, and $4.5 \%$, respectively. All the above variance contributions passed the significance test. Figure 2 is a variation diagram of the characteristic vectors of the zonal wind, meridional wind, and temperature fields with height over the Antigua station. As shown in Figure 2, the values for the first mode of the zonal wind field are basically positive, which reflects the fact that the changes in the zonal wind field at this station are basically consistent, whereas the first mode of the meridional wind field has more positive values than do the other modes. Therefore, the first mode is the most important form for the wind field changes at this station. The temperature field diagram shows that the values of the first mode are all positive, so the first mode is also the most dominant component of the temperature field.

If the number of effective soundings in a certain month is at least 2 , the average value can be calculated as the average characteristic value for that month. Figure 3 shows the monthly (a) zonal wind field anomaly and (b) meridional wind field anomaly over the Antigua station from 1976 to 1990, and the monthly (c) temperature field anomaly from 1964 to 1990, where the values of easterly and northerly winds are positive. The white space in the figure indicates that the number of effective soundings is less than 2 in that month. In the effective wind field data, it can be seen that the easterly wind usually appears in winter, with a different time and height every year, and the maximum value is usually between 40 and $55 \mathrm{~km}$. The westerly wind usually occurs in summer, with the maximum value between 40 and $60 \mathrm{~m} \cdot \mathrm{s}^{-1}$, and the maximum value of the westerly wind is usually slightly lower than the maximum height of the easterly wind. Figure $3 \mathrm{~b}$ shows that the northerly wind is dominant at 40 to $55 \mathrm{~km}$, and the maximum northerly wind is likely to occur every year in four seasons. The maximum value is between 10 and $20 \mathrm{~m} \cdot \mathrm{s}^{-1}$, and the meridional wind speed 

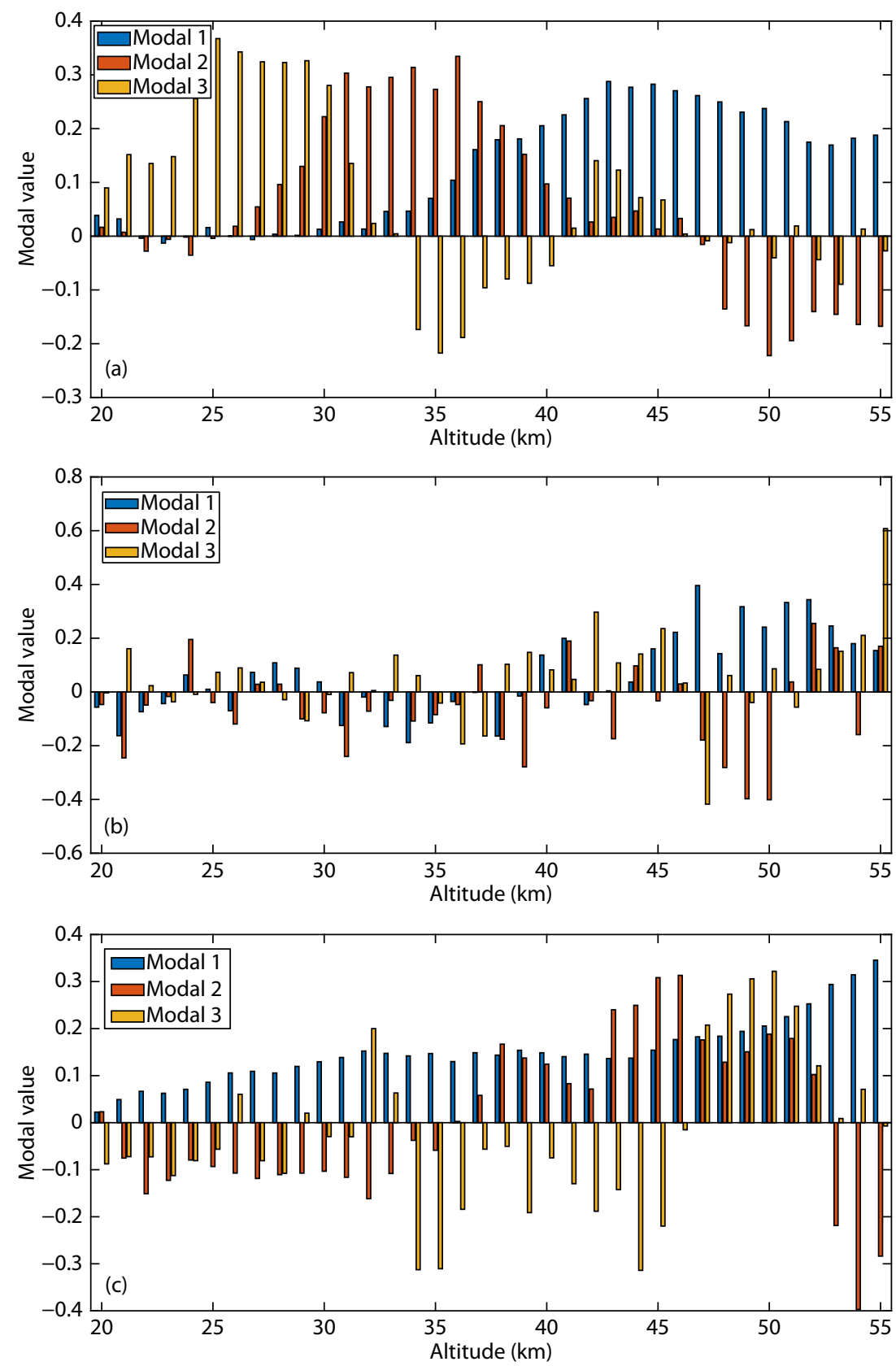

Figure 2. Variation in characteristic vectors of (a) the zonal wind field, (b) the meridional wind field, and (c) the temperature field with height over the Antigua station.

under $40 \mathrm{~km}$ is close to zero. The northerly wind is clearly stronger than the southerly wind. According to the temperature shown in Figure $3 c$, among the effective temperature data, the high value usually appeared at $30-55 \mathrm{~km}$ from 1965 to 1974 , and the low value appeared more frequently during 1975-1987. In addition, the low value was possible at all heights.

In contrast to the monthly average, the annual average characteristic value has no requirements for the number of annual effective soundings. Figure 4 shows the time coefficients for the annual (a) zonal wind field anomaly, (b) meridional wind field anomaly, and (c) temperature field anomaly over the Antigua station. As shown in Figure $4 a$, within 14 years, the annual latitudinal wind speed anomaly at $20 \mathrm{~km}$ above the station presented a significant upward trend with time. It was in a downward trend from 1976 to 1979, fluctuated from 1980 to 1984, and rapidly increased from 1984 to 1990 . The meridional wind speed (Figure 4b) fluctuated between 1976 and 1986, with little overall change in trend. A significant downward trend occurred after 1986, which caused an overall downward trend in 2014. The time coefficient of the temperature field (Figure 4c) shows that the temperature field was in an obvious downward trend from 1965 to 1975 and changed little from 1976 to 1982. A mutation occurred in 1983, and the temperature rose rapidly. From 1984 to 1990, it declined rapidly and then rose to the level of the late 1970s. Overall, the temperature showed a significant decline.

In Figure 3, three distinct levels of variation of feature vectors can 

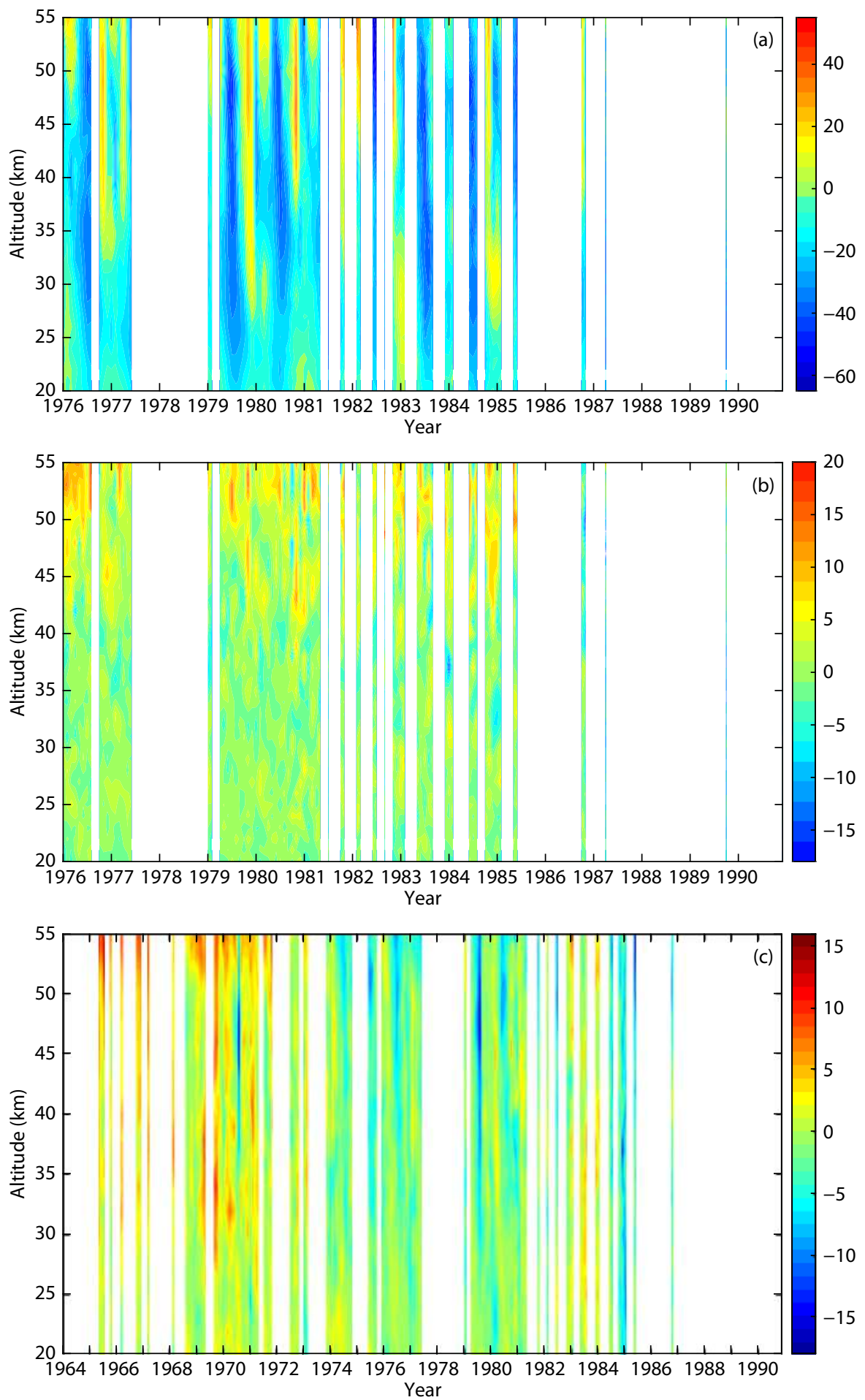

Figure 3. The monthly (a) zonal wind field anomaly and (b) meridional wind field anomaly and the monthly (c) temperature field anomaly over the Antigua station from 1976 to 1990.

be observed at a height of 20 to $55 \mathrm{~km}$. To more clearly reflect the difference in levels, 20,35, and $55 \mathrm{~km}$ were selected for research as representative heights of the three levels.

\subsection{Feature Analysis of the Antigua Station at $\mathbf{2 0} \mathbf{~ k m}$}

The Mann-Kendall test was performed on the annual latitudinal wind field anomaly at $20 \mathrm{~km}$ above the Antigua station (Figure 5a). According to the UF curve, the wind speed was basically in a downward trend before 1988 except for 1978, whereas after 1988, the value of the UF curve turned positive and the wind speed began to change into an upward trend. Moreover, the intersection point of UF and UB was within the critical boundary; that is, it began to mutate in the spring of 1989. Because the change range never exceeded the critical boundary, the wind speed trend was not significant. A wavelet analysis (Figure $5 \mathrm{~b}$ ) was then carried 

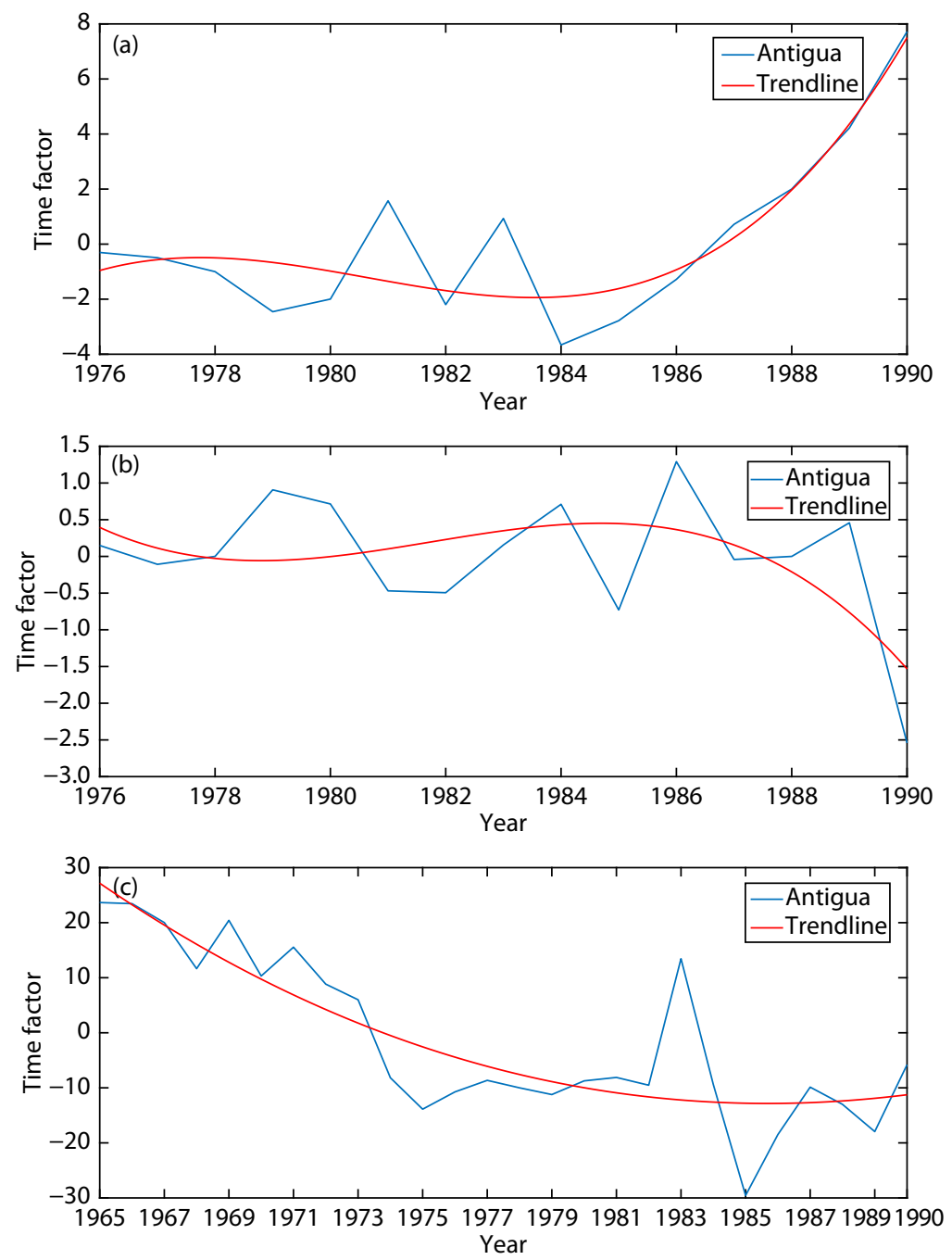

Figure 4. Time coefficients of the annual (a) zonal wind field anomaly, (b) meridional wind field anomaly, and (c) temperature field anomaly over the Antigua station.

out. The upper part of the distribution was high frequency, and the isolines were relatively dense. The contour lines in the lower part were sparse and low frequency, and the corresponding scale period of oscillation was long. The wavelet coefficient reached its maximum value 1.6 in 1978, when the frequency was 5, and in 1981 , when the frequency was 4 . Its minimum value -2 appeared in 1977 and 1980, when the frequency was 4.5. In terms of the scale change, the site had a significant quasi-5-year cycle and a quasi-2-year short cycle within 14 years.

Figure $5 \mathrm{c}$ and $5 \mathrm{~d}$ show the Mann-Kendall test curve and wavelet transform of the annual meridional wind field anomaly at $20 \mathrm{~km}$ above the Antigua station. According to results of the MannKendall test, the UF curve was positive from 1978 to 1981; that is, the meridional wind speed was basically on a downward trend from 1976 to 1977 and from 1982 to 1985 . But it was on an upward trend from 1978 to 1981 , fluctuated from 1986 to 1989 , and was finally on a downward trend from 1990. Both the UF and UB curves are located within the critical boundary, so an abrupt wind speed trend was not obvious. From the wavelet analysis, it can be seen that the lower part of the distribution map is in the low-frequency region, the isolines are very sparse, and the correspond- ing scale period is relatively long. In the high-frequency region in upper part, the isolines are dense. The wavelet coefficient reached its maximum value 0.6 in 1989, when the frequency was 4, and its minimum value -0.6 appeared in 1988 , when the frequency was the same. In terms of scale cycles, significant quasi-5-year cycles and quasi-2-year short cycles occurred.

The annual temperature field anomaly at $20 \mathrm{~km}$ above the Antigua station was then analyzed. The results of the Mann-Kendall test (Figure 5e) showed that the UF curve was positive from 1969 to 1977 , so the temperature field was on an upward trend, but it turned downward after 1977. From the location of the intersection point of the UF and UB curves, the downward trend after 1977 was judged to be a sudden phenomenon. In particular, the value of the UF curve from 1985 to 1988 exceeded the critical value of the significance level of 0.05 , so the temperature field showed a significant downward trend during this period. Results of the wavelet analysis (Figure 5f) showed that the lower part of the time scale was low frequency, the upper part was high frequency, and the middle isoline was denser than the upper part; thus, the middle part corresponded to the shortest oscillation period. The wavelet coefficient reached its maximum value 1.1 in 


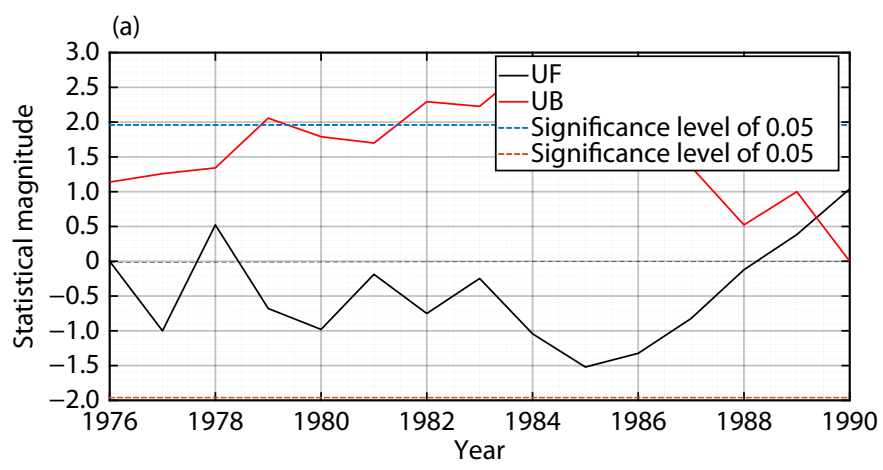

(b) Wavelet transform coefficient distribution diagram

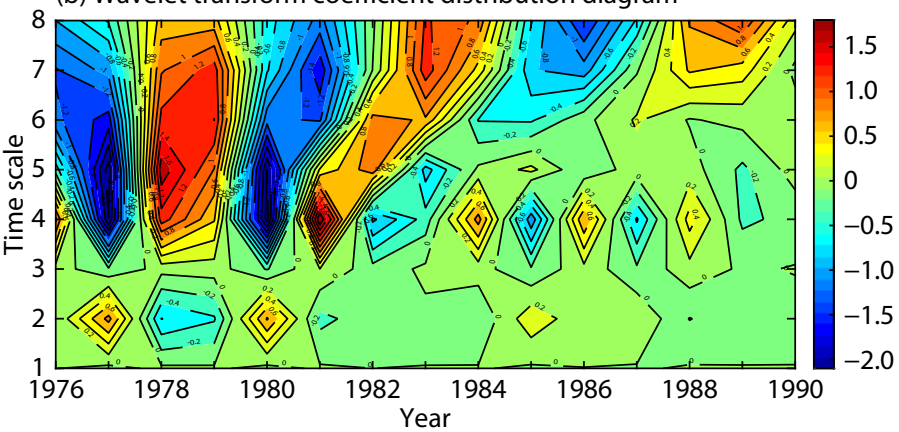

(c)

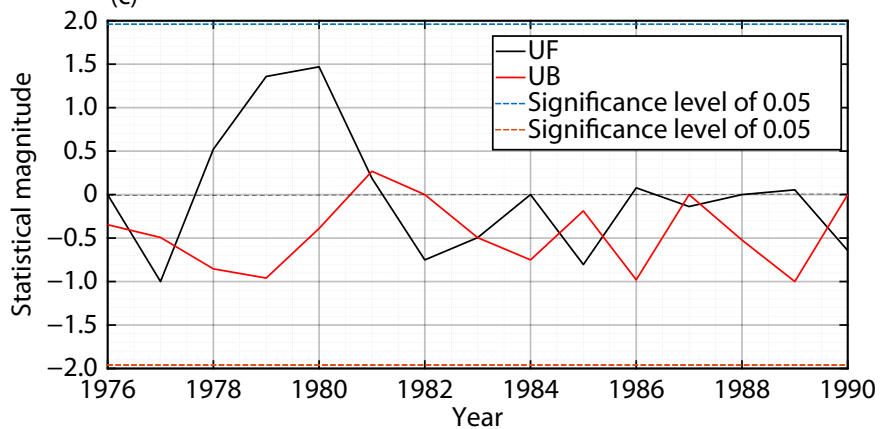

(d) Wavelet transform coefficient distribution diagram

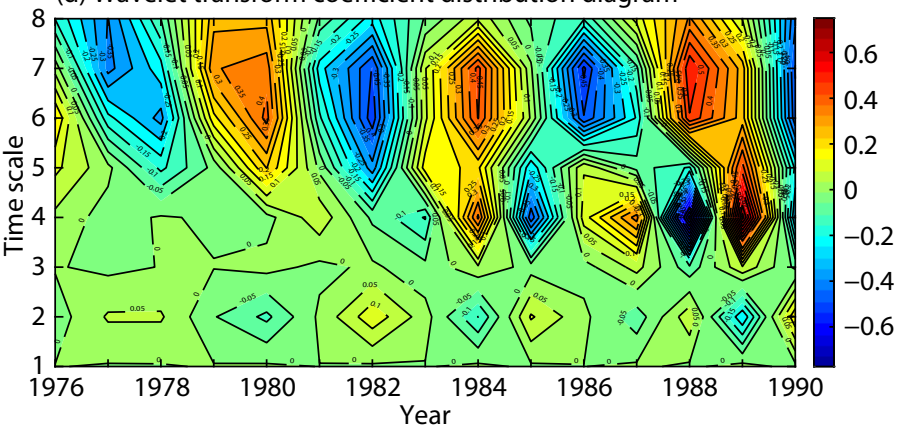

(e)

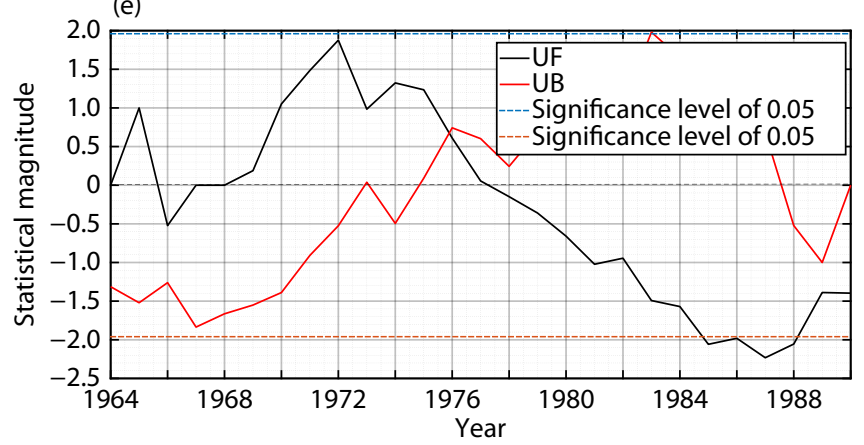

(f) Wavelet transform coefficient distribution diagram

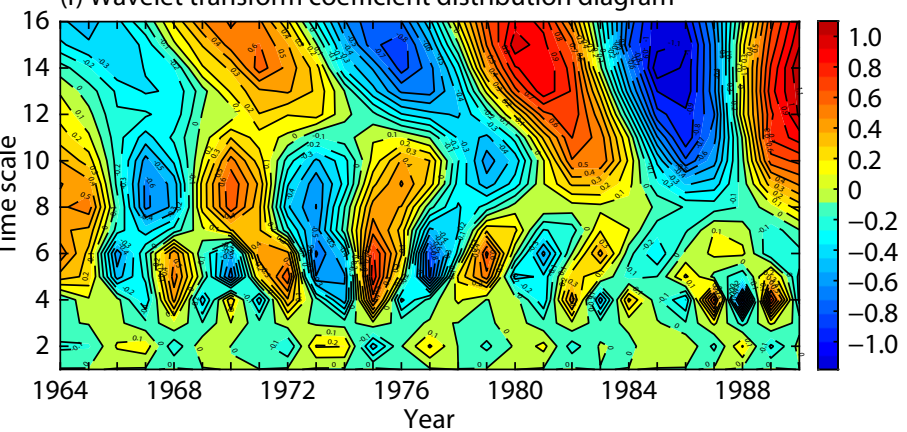

Figure 5. Mann-Kendall test curve and wavelet transform coefficient distribution diagram of the annual ( $a$, b) zonal wind field anomaly, the annual $(c, d)$ meridional wind field anomaly, and the annual $(e, f)$ temperature field anomaly at $20 \mathrm{~km}$ above the Antigua station.

1980 , when the frequency was 15 , and reached its minimum value -1.1 in 1990, when the frequency was 13 . For 16 years, significant quasi-10-year, quasi-6-year, and quasi-4-year short cycles occurred in the temperature field.

\subsection{Feature Analysis of the Antigua Station at $\mathbf{3 5} \mathbf{~ k m}$}

When the characteristics of the annual zonal wind field anomaly at $35 \mathrm{~km}$ above the Antigua station were analyzed, the Mann-Kendall test (Figure 6a) showed that the value of the UF curve was negative from 1980 to 1981 and 1983, so the zonal wind speed was rising from 1976 to 1979 , from 1985 to 1990 and in 1982, but was declining from 1980 to 1981 and in 1983. The intersection point of the UF curve and the UB curve lies within the critical boundary; that is, the zonal wind speed changed suddenly in 1986. Because the value of the UF curve exceeded the critical boundary in 1989, the upward trend after 1986 was very significant. According to the wavelet analysis (Figure 6b), the upper part of the time scale is the high-frequency region, the lower part is the low-frequency region, and the middle part is denser than the upper contour line, so the middle scale period is shorter than the upper part. The wavelet coefficient reached its maximum value 4.8 in 1978, 1982, and 1989, when the frequency was 5, and its minimum value -5 in 1980 and 1987, when the frequency was 5 . In terms of scale variation, a significant quasi-5-year cycle and a short 3.5-year cycle occurred at the site within 14 years.

Figure $6 c$ and $6 d$ show the Mann-Kendall test curves and the wavelet transform distribution of the annual meridional wind field anomaly at $35 \mathrm{~km}$ above the Antigua station. According to results of the Mann-Kendall test, from 1976 to 1986, the values of the UF curve fluctuated near the zero line, so the wind speed also changed repeatedly during the declining and rising trends. After 1986, the value of the UF curve continued to be negative and did not exceed the critical line, so the wind speed showed a continuous downward trend. The intersection point of the UF and UB curves occurred in 1989, so the downward trend was a sudden phenomenon. Because this sudden point was within the critical boundary, the downward trend was not significant. Results of the wavelet analysis show that the upper part of the time scale is high 

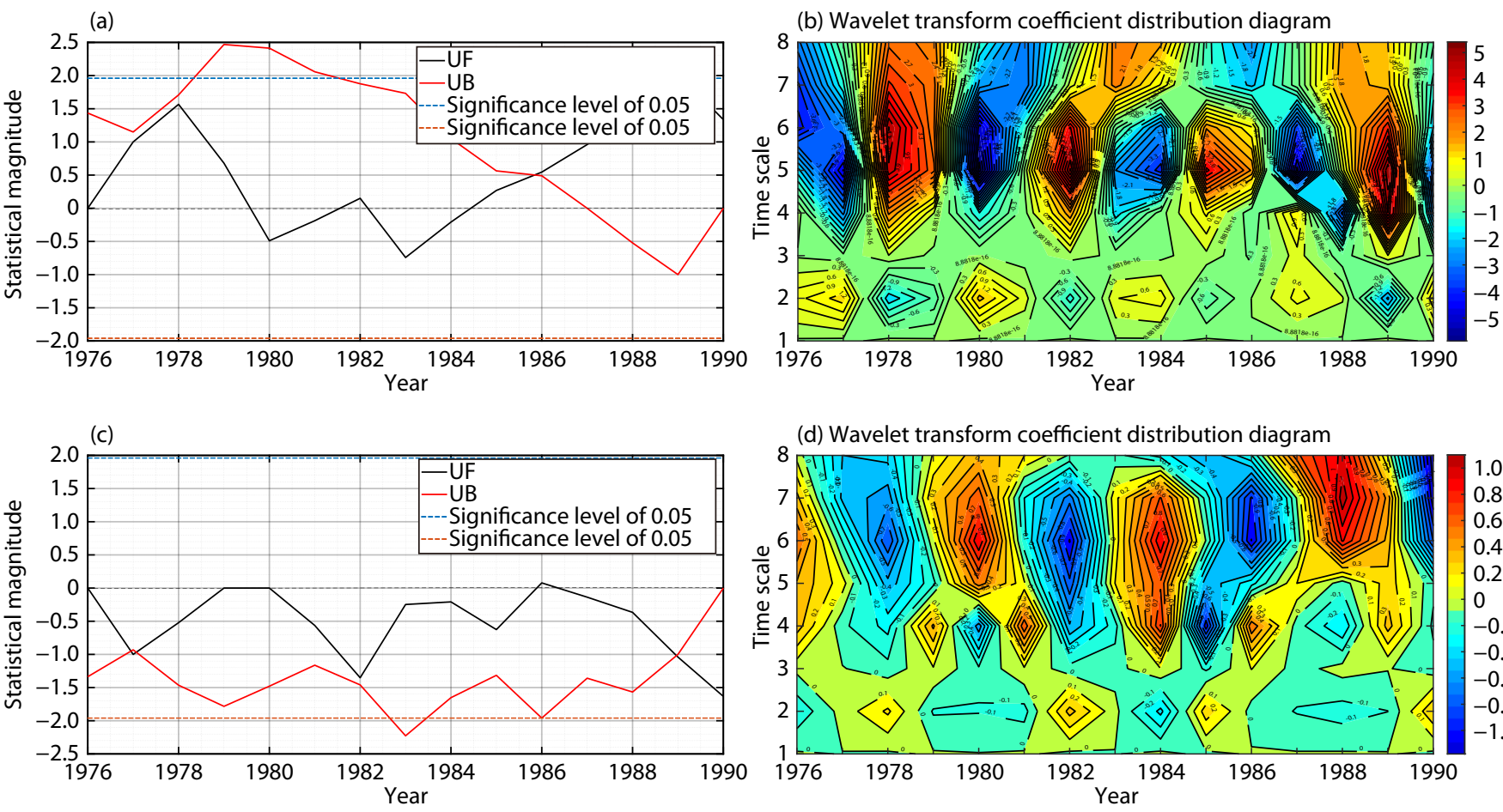

(d) Wavelet transform coefficient distribution diagram
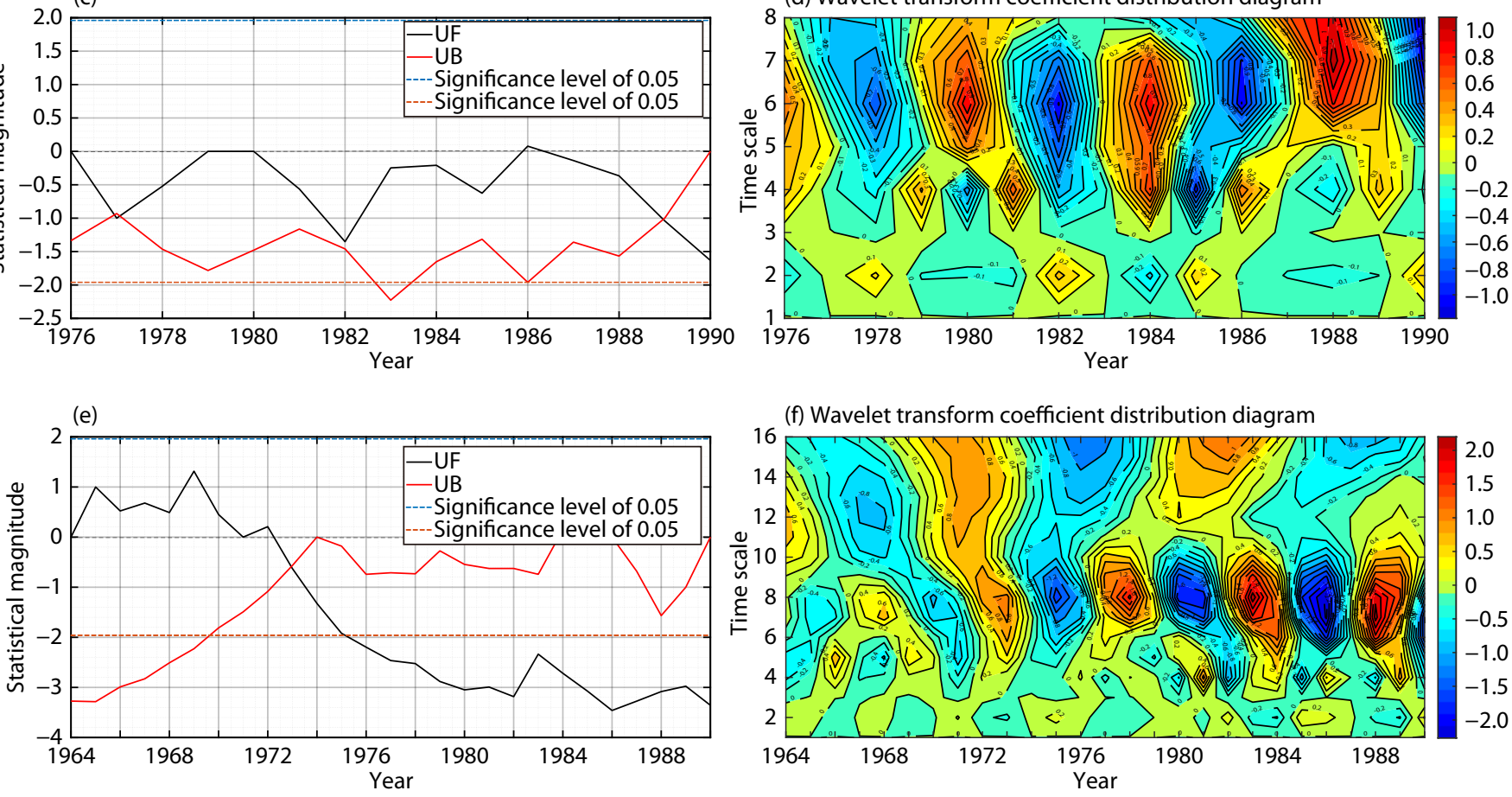

Figure 6. Mann-Kendall test curve and wavelet transform coefficient distribution diagram of $(a, b)$ the annual zonal wind field anomaly, (c, d) the annual meridional wind field anomaly, and $(e, f)$ the annual temperature field anomaly at $35 \mathrm{~km}$ above the Antigua station.

frequency and the lower part is lower frequency. The wavelet coefficient reached its maximum value 1.1 in 1988, when the frequency was 7 , and its minimum value -0.9 in 1986, when the frequency was 6 . The temperature field clearly has a 4.5 -year cycle and a quasi-4-year cycle.

The annual temperature field anomaly at $35 \mathrm{~km}$ above the Antigua station was then analyzed. As shown in Figure $6 \mathrm{e}$, the Mann-Kendall test on the temperature field indicated that the values of the UF curve were positive from 1964 to 1972 and negative from 1972, so the temperature field showed an upward trend from 1964 to 1972 and a downward trend from 1973 to 1990 . The intersection point of the UF curve and the UB curve was located within the critical line in 1973, so the downward trend was a sudden phenomenon. Because the value of the UF curve exceeded the critical line after 1975, the downward trend of the temperature field was very significant. Results of the wavelet analysis (Figure 6 f) show that the middle part of the time scale is still high frequency, the upper contour line is denser than the lower one, and the middle period is less dense than the upper period. The wave- let coefficient reached its maximum value 2 in 1983, when the frequency was 8 , and in 1988, when the frequency was 7 , and its minimum value -2 in 1986, when the frequency was 7 . As shown in the figure, quasi-5-year and quasi-11-year periods appear in the annual temperature field anomaly.

\subsection{Feature Analysis of the Antigua Station at $\mathbf{5 5} \mathbf{~ k m}$}

The annual zonal wind field anomaly at $55 \mathrm{~km}$ above the Antigua station was first analyzed. As shown in Figure 7a, the Mann-Kendall test indicated that the value of the UF curve from 1976 to 1986 changed in the attachment of the zero line, leading to an alternation in declining and rising trends. After 1986, the values of the UF curve were all positive, so the wind speed changed to an upward trend. The intersection points of the UF and UB curves were all within the critical boundary, so the trend changed into a sudden phenomenon. Moreover, because the values of the UF curve did not exceed the critical boundary, the upward trend was not significant. Results of the wavelet analysis (Figure 7b) show that after 1982, the contour lines became dense instead of sparse, the upper part is high frequency, and the lower part is still low fre- 


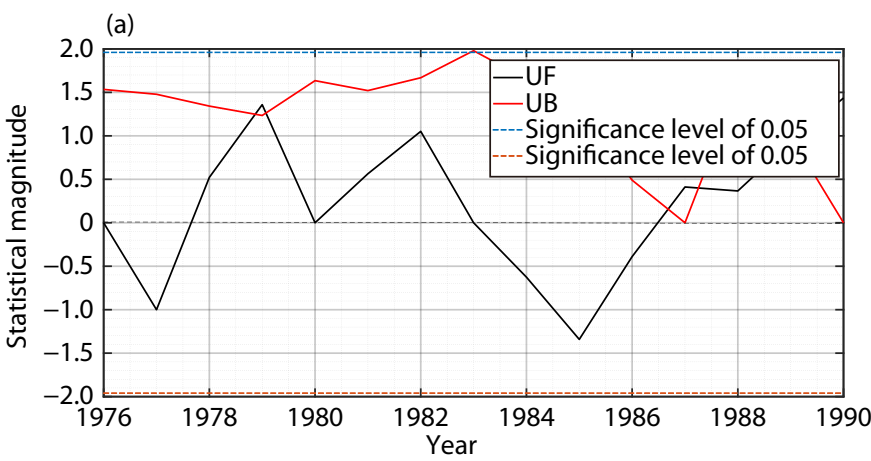

(b) Wavelet transform coefficient distribution diagram
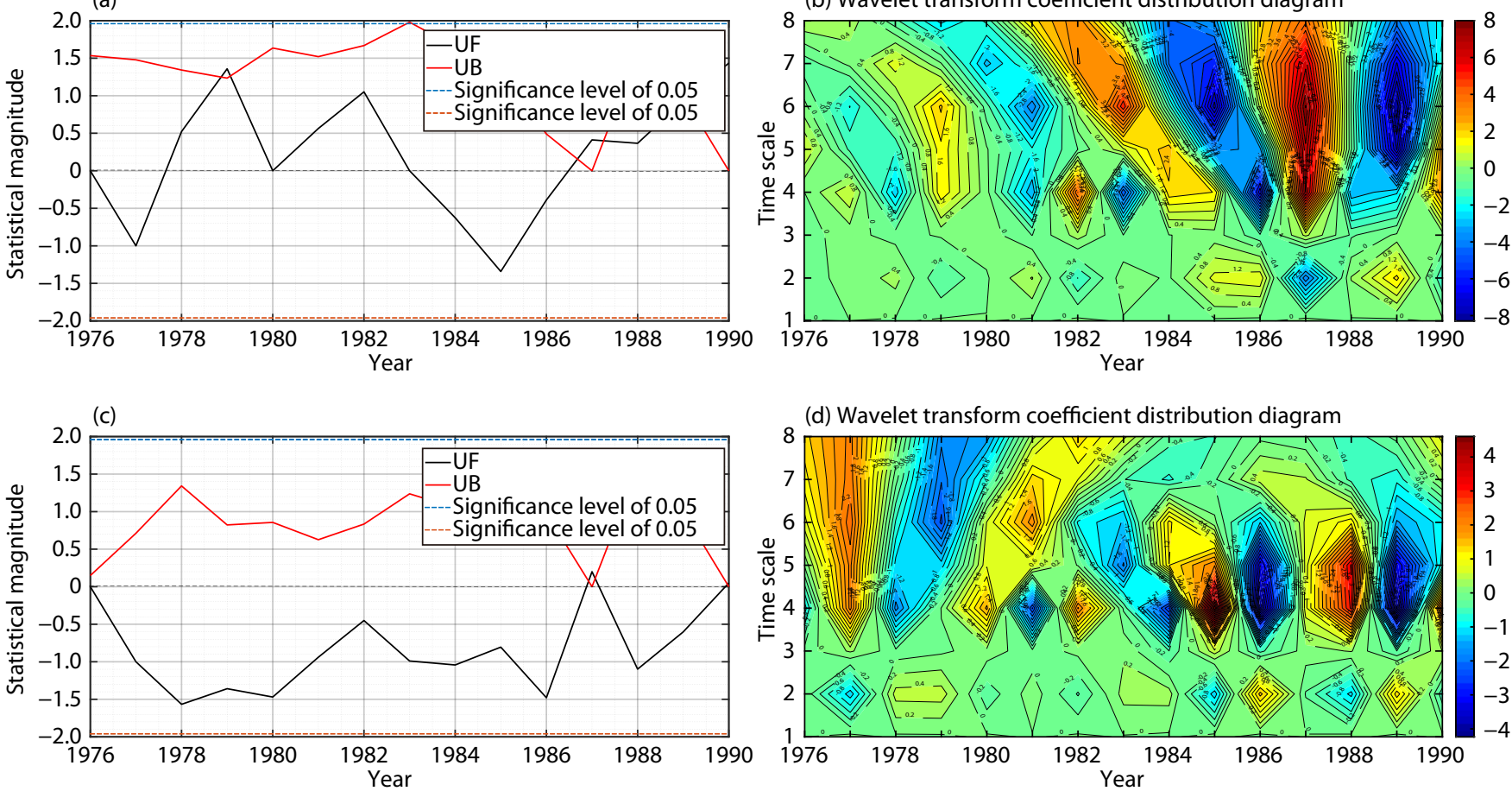

(d) Wavelet transform coefficient distribution diagram
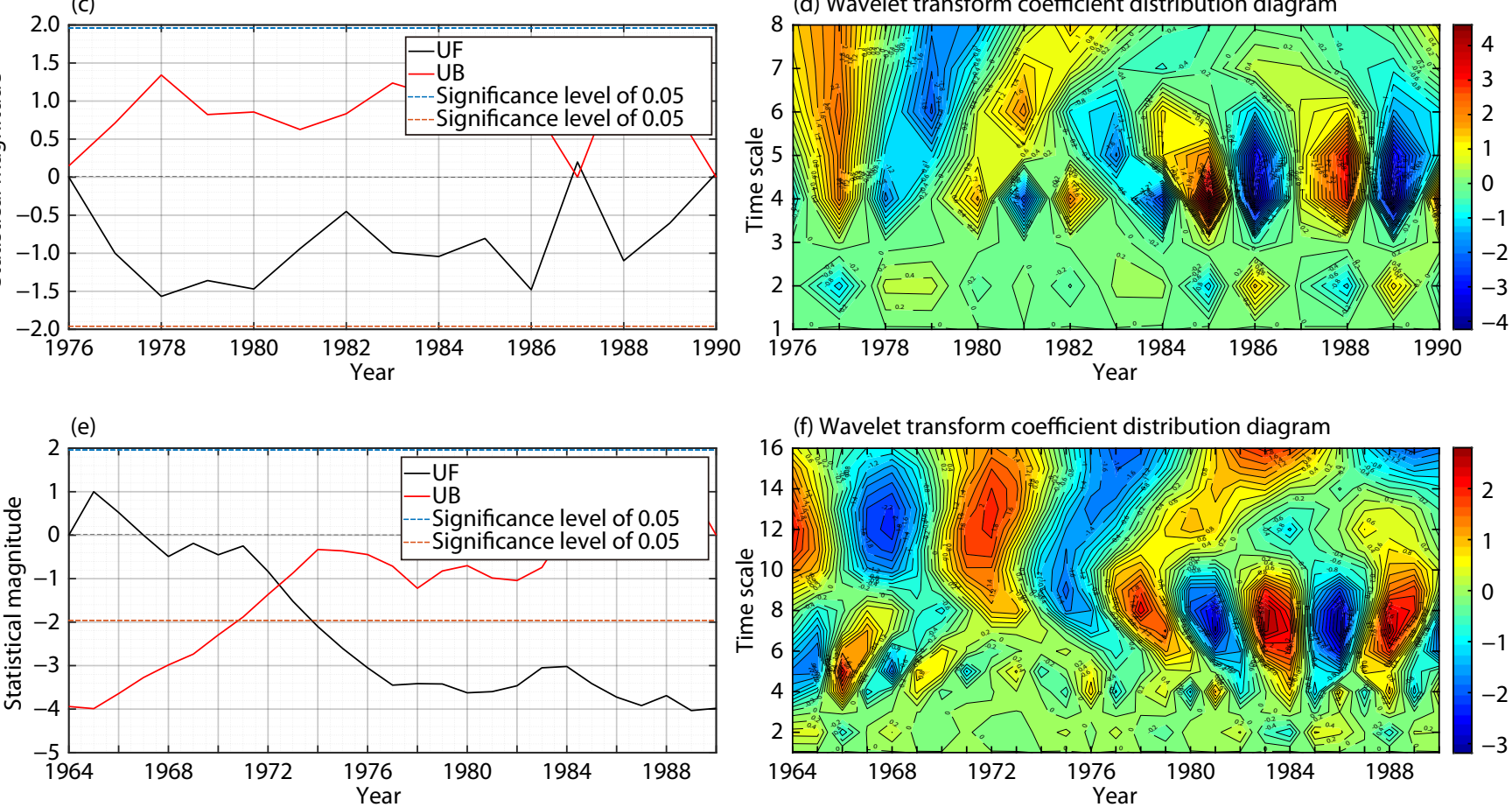

Figure 7. Mann-Kendall test curve and wavelet transform coefficient distribution diagram of $(a, b)$ the annual zonal wind field anomaly, $(c, d)$ the annual meridional wind field anomaly, and $(e, f)$ the annual temperature field anomaly at $55 \mathrm{~km}$ above the Antigua station.

quency. From 1976 to 1982 , all the time scales were basically low frequency. The wavelet coefficient reached its minimum value -8 in 1985 and 1989, when the frequency was 6, and its maximum value 8 in 1987, when the frequency was the same. Quasi-5-year cycles and quasi-3-year short cycles appear in the figure.

The annual meridional wind field anomaly at $55 \mathrm{~km}$ above the Antigua station was then analyzed. The Mann-Kendall test (Figure 7c) showed that the UF curve value was always negative from 1976 to 1986; that is, the wind speed was always in a downward trend. The curve was positive in 1987 and 1990, so the UF curve was in an upward trend in these 2 years. The intersection points of the UF curve and UB curve were in 1987 and 1990, indicating that the upward trend was in a sudden state of change. The value of the UF curve was always within the critical boundary, so the changing trend of the wind speed was not significant. Results of the wavelet analysis (Figure 7d) showed that the upper part of the time scale from 1976 to 1982 was high frequency, the middle part of the time scale from 1982 to 1990 was high frequency, and the upper part of the time scale from 1982 to 1990 was low frequency.
It reached the minimum value -4 in 1986 and 1989, when the wavelet coefficient was 4 , and it reached the maximum value 4 in 1985. In terms of scale cycles, quasi-4-year cycles and quasi-2-year cycles appear from 1976 to 1982, and quasi-3-year cycles and quasi-2-year cycles appear from 1982 to 1990.

Figure $7 e$ and $7 f$ show the Mann-Kendall test curve and the wavelet transform coefficient distribution diagram of the annual temperature field anomaly at $55 \mathrm{~km}$ above the Antigua station. According to the Mann-Kendall test, between 1964 and 1967, the value of the UF curve was positive and the temperature field was on the rise. After 1967, the value of the UF curve turned negative, so the temperature field began a declining trend. The intersection point of the UF and UB curves was in 1972, and the intersection point was within the critical boundary, so the downward trend was a sudden phenomenon. Because the value of the UF curve exceeded the critical boundary after 1974, the downward trend was very significant. Results of the wavelet analysis showed that the time scale above 3 was basically high frequency, and the isolines from 1977 to 1990 were denser than those from 1964 to 
1976. It reached its maximum value 2.6 in 1983 and 1988, when the wavelet coefficient was 8 , and its minimum value -3 in 1981 and 1986. In terms of scale cycles, quasi-9-year cycles and quasi-3year cycles appear between 1964 and 1976, and quasi-5-year cycles appear between 1976 and 1990.

\section{Conclusions}

In this paper, the time variation characteristics of the wind field and temperature field at different levels were analyzed by using data on the velocity field and temperature field from sounding rockets over the Antigua station. The following conclusions were drawn:

(1) From 1976 to 1990, the overall zonal wind speed showed a significant upward trend with the year. At a height of $20 \mathrm{~km}, 1988$ was the turning point, and the trend changed from declining to rising. At an altitude of $35 \mathrm{~km}$, the upward trend was particularly significant after 1986. When the altitude was $55 \mathrm{~km}$, the trend also turned from descending to rising after 1986.

(2) From 1976 to 1990, the overall change in meridional wind speed showed a downward trend over 14 years. At a height of 20 $\mathrm{km}$, two obvious descending processes occurred, but they always fluctuated in the ascending and descending process, and the descending trend in 1990 was not obvious. At an altitude of $35 \mathrm{~km}$, a continuous downward trend was observed after 1986. At a height of $55 \mathrm{~km}$, the wind field exhibited a downward trend except in 1986 and 1990.

(3) The temperature field showed a significant decreasing trend from 1965 to 1990. At an altitude of $20 \mathrm{~km}$, it changed from an upward trend to a significant downward trend in 1977. At an altitude of $35 \mathrm{~km}, 1973$ was the turning point when the trend changed from rising to falling. At a height of $55 \mathrm{~km}$, it changed to a significant downward trend in 1967.

(4) According to results of the wavelet analysis, the zonal wind field and the meridional wind field both had significant characteristics of a quasi-5-year cycle and a quasi-2-year short cycle change at an altitude of $20 \mathrm{~km}$, and the temperature field had characteristics of a quasi-10-year cycle, a quasi-6-year cycle, and a quasi-4year short cycle change. At an altitude of $35 \mathrm{~km}$, the zonal wind field and the meridional wind field had significant periodic variation characteristics of approximately 5 and 4 years, whereas the temperature field had periodic variation characteristics of a quasi5-year cycle and a quasi-11-year cycle. At an altitude of $55 \mathrm{~km}$, the zonal wind field had obvious variation characteristics of a quasi-5year cycle and a quasi-3-year short cycle. The meridional wind field had quasi-4-year and quasi-2-year periodic variation characteristics from 1976 to 1982, and quasi-3-year and quasi-2-year periodic characteristics from 1982 to 1990. Between 1964 and 1976 , the temperature field had characteristics of a quasi-9-year cycle and a quasi-3-year cycle, and quasi-5-year cycle variation characteristics appeared between 1976 and 1990.

\section{Acknowledgments}

The study was supported by the National Natural Science Foundation of China (Grant no. 41875045).

\section{References}

Brasseur, G., Hitchman, M. H., Simon, P. C., and De Rudder, A. (1988). Ozone reduction in the 1980's: a model simulation of anthropogenic and solar perturbations. Geophys. Res. Lett., 15(12), 1361-1364. https://doi.org/10.1029/GL015i012p01361

Brühl, C., and Crutzen, P. J. (1988). Scenarios of possible changes in atmospheric temperatures and ozone concentrations due to man's activities, estimated with a one-dimensional coupled photochemical climate model. Climate Dyn., 2(3), 173-203. https://doi.org/10.1007/BF01053474

Chang, Q. H., Yang, G. T., Song, J., and Gong, S. S. (2006). The stability of the middle atmosphere (30-60 km) over Wuhan by Rayleigh lidar. Chin. Sci. Bull., 51(21), 2657-2661. https://doi.org/10.1007/s11434-006-2160-7

Chen, B. Q., Liu, Y., Liu, L. K., Shen, X. Y., and Zhang, Y. L. (2018). Characteristics of spatial-temporal distribution of the stratospheric quasi-zero wind layer in low-latitude regions. Climatic Environ. Res., 23(6), 657-669. https://doi.org/10.3878/j.issn.1006-9585.2018.17086

Frierson, D. M. W. (2006). Robust increases in midlatitude static stability in simulations of global warming. Geophys. Res. Lett., 33(24), L24816. https://doi.org/10.1029/2006gl027504

Frierson, D. M. W., and Davis, N. A. (2011). The seasonal cycle of midlatitude static stability over land and ocean in global reanalyses. Geophys. Res. Lett., 38(13), L13803. https://doi.org/10.1029/2011GL047747

Han, P. C., and Jian, M. Q. (2016). Interdecadal variability of quasi-biennial oscillation of stratospheric zonal wind. J. Trop. Meteor., 32(4), 458-466. https://doi.org/10.16032/j.issn.1004-4965.2016.04.003

Held, I. M., and O'Brien, E. (1992). Quasigeostrophic turbulence in a three-layer model: effects of vertical structure in the mean shear. J. Atmos. Sci., 49(19), 1861-1870. https://doi.org/10.1175/1520-0469(1992)0492.0.CO;2

Huang, R. H., Chen, W., Wei, K., Wang, L., and Huangpu, J. L. (2018). Atmospheric dynamics in the stratosphere and its interaction with tropospheric processes: progress and problems. Chin. J. Atmos. Sci., 42(3), 463-487. https://doi.org/10.3878/j.issn.1006-9895.1802.17250

Juckes, M. N. (2000). The static stability of the midlatitude troposphere: the relevance of moisture. J. Atmos. Sci., 57(18), 3050-3057. https://doi.org/10.1175/1520-0469(2000)057<3050:TSSOTM>2.0.CO;2

Liu, J., Chen, J. Y., Wu, S. J., and Luo, C. (2017). Research on the characteristics and laws of wind field environmental changes in the stratosphere in Xinjiang. In The Fourth China High Resolution Earth Observation Conference CHREOC. Wuhan.

Liu, M. Z., Ma, M., and Liu, X. (2016). Rocket sounding observations of stratospheric winds in Kwajalein Island $\left(8^{\circ} \mathrm{N}, 167^{\circ} \mathrm{E}\right)$ and their comparisons with HWM07 and CIRA86. J. Henan Normal Univ. (Nat. Sci. Ed.), 44(6), 1-8. https://doi.org/10.16366/j.cnki.1000-2367.2016.06.001

Ramaswamy, V., Chanin, M. L., Angell, J., Barnett, J., Gaffen, D., Gelman, M., Keckhut, P., Koshelkov, Y., Labitzke K., ... Swinbank, R. (2001). Stratospheric temperature trends: observations and model simulations. Rev. Geophys., 39(1), 71-122. https://doi.org/10.1029/1999rg000065

Santer, B. D., Taylor, K. E., Wigley, T. M. L., Johns, T. C., Jones, P. D., Karoly, D. J., Mitchell, J. F. B., Oort, A. H., Penner, J. E., ... Tett, S. (1996). A search for human influences on the thermal structure of the atmosphere. Nature, 382(6586), 39-46. https://doi.org/10.1038/382039a0

Trenberth, K. E., and Stepaniak, D. P. (2003). Seamless poleward atmospheric energy transports and implications for the Hadley circulation. J. Climate, 16(22), 3706-3722. https://doi.org/10.1175/15200442(2003)016<3706:spaeta>2.0.co;2

Wang, L. J., Chen, Z. Y., Ling, C., and Lü, R. D. (2015). Decreasing trend of the middle atmospheric static stability in historical data from rocketsonde network. Acta Phys. Sin., 64(16), 169201. https://doi.org/10.7498/aps.64.169201

Wei, F. Y. (1999). Modern Climate Statistical Diagnosis and Prediction Technology (in Chinese). Beijing: Meteorological Press.

$\mathrm{Wu}, \mathrm{Y}$. F. (1994). Observations of small scale wind shears in the mesosphere. Chin. J. Space Sci., 14(2), 151-156.

Xiao, W. H., Fu, Y., Du, X. Y., and Gao, T. C. (2012). Analysis of deriving stratospheric atmospheric winds from COSMIC radio occultation data. 
Geomatics Inf. Sci. Wuhan Univ., 37(2), 199-204. https://doi.org/10.13203/j.whugis2012.02.025

Xiao, Y. S. (1984). The effects of vertical stratification of temperature and of vertical wind shear on the development of synoptic systems. Acta Meteor. Sin., 42(3), 279-289. https://doi.org/10.11676/qxxb1984.033

Xu, B. Q., Wu, T. T., and Li, W. H. (2014). Screening of calculation methods for wind shear exponent. Trans. Chin. Soc. Agric. Eng., 30(16), 188-194. https://doi.org/10.3969/j.issn.1002-6819.2014.16.025
Xu, J., and Powell, A. M. (2010). Inter-comparison of temperature variability from multiple radiosondes, reanalyses products and CMIP5/IPCC climate model simulation. In Fall Meeting 2010. Washington: American Geophysical Union.

Zhang, M., Xu, X. F., Min, J. Z., and Gao, Q. J. (2015). Advances in low frequency modes studies in middle-high latitude. J. Meteor. Sci., 35(6), 799-806. https://doi.org/10.3969/2014jms.0078 